\title{
Iron and Steel Welding
}

$\mathrm{T}$ HE enormous change in the general outlook on welding which has taken place during the last twelve or fifteen years was never so well exemplified as by the attendance of some nine hundred persons at the first meeting of the symposium on the welding of iron and steel organised by the Iron and Steel Institute with the co-operation of fifteen other scientific and technical societies, and held at the Institution of Civil Engineers on May 2-3. Sir Harold Carpenter presided, and pointed out that the whole question of welding had been raised by Dr. H. J. Gough for the consideration of the Department of Scientific and Industrial Research.

The object of the symposium was of a two-fold character. It was designed in the first place, and mainly, to discover what is now known, and in the second place to map out fields of work for future development. Although welding is still in large measure an empirical art, a considerable amount of fundamental scientific work is now being done, and the results of this have been brought together in a collection of papers which represents by far the most important and comprehensive collection of information on the welding of the ferrous metals which has ever been made. The papers were divided into a series of groups, of which the first dealt with presentday practice and problems connected with welding in the engineering industries. Shipbuilding, bridge and structural engineering, railway material and pressure vessels, formed one sub-section of this group, the other dealing with the aeronautical and automobile industries, the production of chain, the electrical, heavy engineering and machinery industries and the welding of iron and steel castings and of wrought iron.

Group 2 was concerned with the practice and technique of welding, including the apparatus and plant required. The metallurgy of welding, and the questions of specifications, inspection and testing formed Groups 3 and 4. It will come as a surprise to many to discover how much real research is being done, and how fundamental are the advances which are being made, at any rate in certain directions.

From the various papers and discussions certain suggestions emerge regarding the lines on which future development and research might usefully proceed. These include :

(1) The development of plant for electric welding in which the current is automatically adjustable to suit the rate of deposit, together with the necessary control of the are.

(2) Despite the work which has already been done, there are still very considerable gaps and discrepancies in our information regarding the factors which affect the fatigue resistance of all types of welded joints, particularly in comparison with similar solid, bolted or riveted constructions, and extensive research work on this point is most essential.

(3) The investigation of the effect on the fatigue strength of various types of treatment and electrodes and the comparative influence of alternating and direct current.

(4) The development of forms of welded construction which are based on a real knowledge of the fatigue properties of the welds for dynamically loaded structures (such as bridges).

(5) Work on the welding of the high carbon and alloy steels.

(6) Work on non-destructive methods of testing welded joints.

No aspect of welding, so far as it is applied to iron and steel, was omitted from this highly successful symposium. The most grateful thanks of producers and users of welded structures are due to those responsible for the meeting on one hand, and the authors of the papers on the other. The only note of a critical nature which can possibly be struck is the fact that the material presented was of such enormous dimensions that the time available for its discussion was inevitably greatly restricted. A further discussion of this material at some future date would form a fitting corollary to the meeting already held.
F. C. T.

\section{Royal Observatory, Greenwich}

Annual Visitation

$\mathrm{T}$ HE Astronomer Royal read his report to the Board of Visitors of the Royal Observatory, Greenwich, on the occasion of the annual visitation of the Observatory on June 1.

The construction of the new reversible transit circle has been completed by Messrs. Cooke, Troughton and Simms, Ltd., and the instrument is undergoing final tests. The construction of the two glass circles of 28 inches diameter, and the etching of divisions spaced at intervals of 5 minutes of are have been carried out successfully. When completed, the new transit circle will be housed in the Christie enclosure next the Yapp 36-inch reflector. A contract for a slit spectrograph for use with the latter telescope has been placed with Messrs. Adam Hilger, Ltd. This spectrograph is designed for use with one or three prisms at will, the optical parts being made from ultra-violet glass giving good transmission down to $3500 \mathrm{~A}$.

During the year, 9,576 transit observations were made, including 130 observations of the sun and 94 of the moon. The observations of the moon continue to show a decrease in the correction to the longitude given by Brown's Tables, which were introduced into the Nautical Almanac in 1923. Nova Herculis was observed on the meridian six times above pole and twice below pole. The position for 1935.0 is $\propto 18^{\mathrm{h}} 5^{\mathrm{m}} 39 \cdot 85^{\mathrm{s}}, \delta+45^{\circ} 50^{\prime} 54 \cdot 2^{\prime \prime}$ (Epoch $1934 \cdot 99$ ). 42 plates were exposed on Nova Herculis in the slitless spectrograph attached to the Yapp 36-inch equatorial reflector. All these have been calibrated for photometry, and where possible a comparison star has been included. These plates will provide material for the study of the distribution of energy throughout 